\title{
THE USE OF SPECIFIC PRINCIPLES AND GUIDELINES FOR EFFECTIVE AND EFFICIENT RESTORATION OF CULTURAL HERITAGE BUILDINGS; CASE STUDY JASHAR PASHA MOSQUE IN PRISHTINA
}

\author{
${ }^{1}$ Violeta NUSHI, ${ }^{2}$ Teuta JASHARI-KAJTAZI \\ ${ }^{1,2}$ Department of Architecture, Faculty of Civil Engineering and Architecture \\ University of Prishtina, Bregu i Diellit p.n, Prishtina, Kosovo \\ e-mail: ${ }^{1}$ violeta.nushi@uni-pr.edu, ${ }^{2}$ teuta.kajtazi@uni-pr.edu
}

Received 20 January 2018; accepted 8 March 2018

\begin{abstract}
The aim of this paper is to review and emphasize the development of using the comprehensive guidelines for the latest restoration of cultural heritage buildings, in this particular case the Jashar Pasha Mosque in Prishtina, Kosovo. The importance of using specific guidelines for the restoration plans will encourage all responsible bodies to think more in a structural way as far as historical sites and architectural heritage is concerned. This includes the need to assess more profoundly the necessity of using restoration and conservation guidelines towards more successful management of projects of this nature, ensuring the effective and efficient safeguarding of cultural heritage in Kosovo, in general.
\end{abstract}

Keywords: Restoration, Comprehensive guidelines, Intervention methodologies, Architectural heritage

\section{Objectives}

The main objective of this paper is to contribute towards the review and the use of defined intervention methodologies and design guidelines for structural diagnostics, repair techniques and intervention plan for an architectural heritage example, Jashar Pasha Mosque in Pristina, Kosovo. Its nature and history, starting from the shape, material and arrangement, presents a number of challenges while diagnosing and planning of the restoration is limited when applying current modern legal codes and building standards in Kosovo, taking into consideration not only physical risks, but also cultural values, social consequences, economic aspects and professional competences. In this case, the intention is to establish main principles, to be followed during the 
multi-disciplinary approach for the preparation of restoration plan, including: data acquisition - information and investigation (historical, structural and architectural investigations; survey of the structure; field research and laboratory testing; monitoring). In addition, the structural behavior is incorporated (structural scheme and damage; material characteristics and decay processes; actions taken on the structure and the materials; physical, chemical, and biological actions), as well as diagnosis and safety evaluation (historical analysis; qualitative analysis, which includes both mathematical modeling and testing). To complete the entire process, the analysis of structural damage, materials deterioration and corrective measures (masonry; timber; iron and steel; reinforced concrete) are important components.

\section{Introduction}

The architectural heritage in Kosovo is the foundation for the sustainable development, which could ensure continuity in the use of buildings and endurance from the past to the future. Their durability and sustainability require rapid and efficient influence, to draw the attention of understanding the legal and administrative mechanisms responsible for managing protection, conservation and restoration of buildings with certain architectural heritage value [1]. Nowadays, architectural heritage that belongs to the built cultural heritage has been found to be in a very dangerous and most vulnerable situation within the process of normal ageing and decaying, affected by environmental pollution and significant neglect for protection and preservation. Structures of these monuments and their building materials, suffer not only from deterioration process caused by physical destruction, but also from structural failures caused by inappropriate interventions. In response to the request of immediate intervention within cultural heritage preservation and conservation in Kosovo, this issue has been addressed in a systematic manner. In 2004, the Priority Intervention List (PIL) and Preliminary Technical Assessment (PTA) were prepared and published for the first time, which applies to its major categories, i.e. religious architecture as Mosques, Churches and Monasteries, vernacular architecture such as traditional residential buildings, Kullas and Konaks [2], but also bridges, fortresses and urban centers.

While aiming to guard harmful consequences of insufficient knowledge, leading towards a misuse of technology and ill-considered actions, as well as in order to advance and support the evaluation, definition and implementation of the restoration intervention, the Jashar Pasha Mosque in Prishtina is an important case study. Restoration interventions, including structural and seismic reinforcement, conservation of stone used on the facade, improvement of the walls and interior elements, drainage, infrastructure, etc. were considered minimum requirements for the initiative. In this particular case, the Government, more precisely the Ministry of Culture, Youth and Sport (MCYS) took the initiative and made the decision to prepare and implement the restoration project, with appropriate analysis and proposals, based on significant guidelines for safety restoration of Jashar Pasha Mosque [3].

Amongst all negative elements related to the steps towards the appropriate and professional monument preservation, it is worth mentioning a number of examples that are to be considered as positive intervention cases or success stories in this regard, led 
by the Cultural Heritage without Borders $(\mathrm{CHwB})$. One of them is in the region, more precisely in Albania, known as Babameto house in Gjirokastra [4], and the preservation of Prizren fortress in Kosovo [5].

\section{General information}

The Jashar Pasha Mosque is a stone masonry building of the XIX century, which stands between historic buildings as: Bazar Mosque, Kosovo Museum, Sultan Mehmet Fatih Mosque and Old Hammam. It was listed as a monument under the state protection in 1967, considering its artistic, esthetic and historic values. Contains three main parts: main prayer squared area $(9.43 \mathrm{~m} \times 9.47 \mathrm{~m})$ covered by a single dome, minaret and wooden portico [3].

The praying hall is covered by a dome with pendetives (curved triangles of vaulting in the corners, resting on external bearing walls). In the exterior, the dome is covered with lead sheets and rests on the octagonal shape with eight small arched windows. Main walls are of crushed stone, reinforced using timber sash or ribbon; however, wall finishes are of regularly arranged stone blocks. The internal wall surface is covered with plaster, and each wall has two windows on the lower part and a small one in the upper part of the cubic structure. The wooden structure of portico is erected above stone masonry basement, supported by wooden columns and covered with three pitched wooden roof structures. The portico has been enclosed by glass panels in 2001, while the Minaret stands on the right side of the entrance and consists of a footrest and a tall circular level ending with a balcony. It is followed by a shorter circular level crowned by typical Ottoman conical end, covered with lead sheets. The mosque preserves its original form and is still in use (Fig. 1).

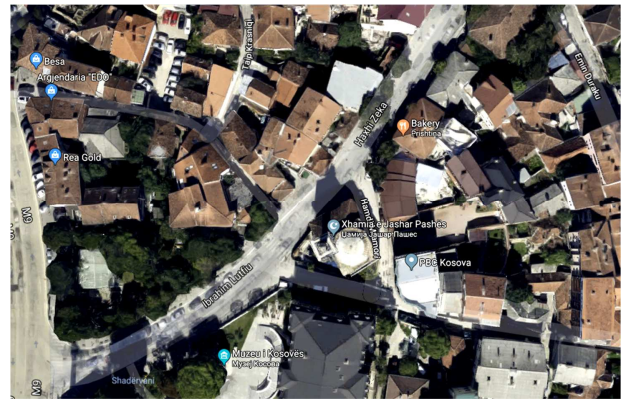

a)

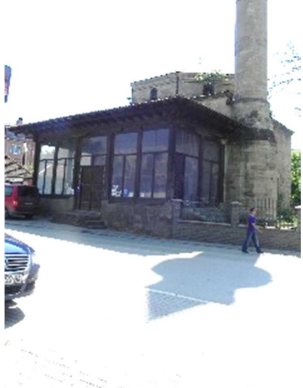

b)

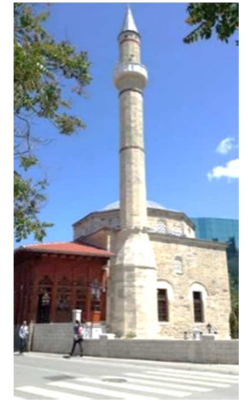

c)

Fig. 1. Main views of Jashar Pasha Mosque; a) the urban environment; b) view with old portico, before the final restoration and c) existing view after the restoration, Sources: a) Google maps site layout, b) Database of cultural heritage of Kosovo, [6] and c) [7]

The interior contains the Mihrab, semicircular niche in the wall oriented towards the qibla (main religion specific orientation). Decorative part in the interior is mainly placed above the Mihrab and along the windows (with floral band). 


\section{Historical, architectural and structural examination, diagnosis, safety evaluation and proposed measures}

Based on the historical survey, understanding the commencement and the significance of the building, the techniques and skills used on Jashar Pasha Mosque, including the subsequent changes, in both the structure and its environment, and the events during the conflict in Kosovo, all resulted in a number of damages [8]. The overloaded Mosque's environmental surrounding with new structures, including permanent vibration caused by heavy traffic, the atmospheric conditions, influence of humidity due to the lack of drainage, condensation, raising damp, the use of inappropriate materials and/or by poor subsequent maintenance, are the main factors that resulted with the structural destabilization, harming the monument fabric, deterioration of the facade stones and interior decorations, as well. Earlier preventive intervention works which included:

a) total enclosure of the portico;

b) mounting of the steel belt on the perimeter of the dome and the minaret, in the exterior;

c) reconstruction of the wooden portico, when it was demolished and recomposed according to the original form, technique and material; and

d) inappropriate mounting of the glass panels in the portico, as well as the inappropriate maintenance of cracked dome cover (which allowed the diffusion of water within the dome structure);

all this caused very serious damage of the building structure (in danger from collapsing due to the dampness caused) (Fig. 2).
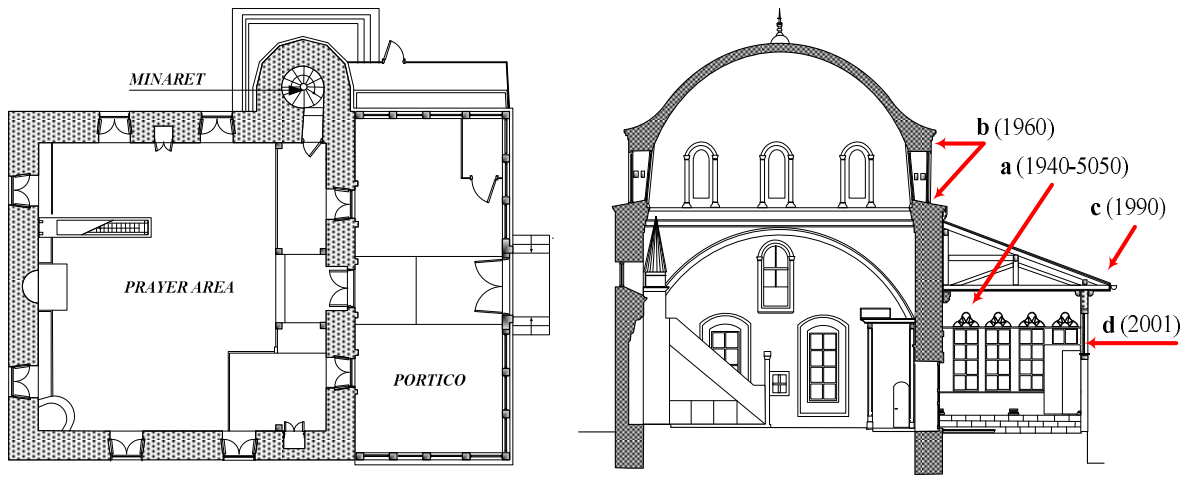

Fig. 2. The layout and intersection illustrating earlier interventions: a) total enclosure of the portico, between 1940-50; b) installation of the steel belt on the perimeter of the dome and the minaret, in 1960's; c) reconstruction of the wooden portico cover, 1990; d) inappropriate installation of glass panels in the portico, 2001 (Source: Authors plot) 
Having in mind that conserving architectural heritage usually requires a multidisciplinary approach, involving the variety of professionals and organizations, the lack of adequate guidelines creates miscommunication between all parties involved. Planning phase for structural conservation requires both qualitative data, based on the direct observation of material decay and structural damage, technical research and quantitative data, based on specific tests and mathematical models used in modern engineering. This combination of approaches, in Kosovo practice, was very difficult to establish due to the misinterpretation of Euro codes, while the lack of clear guidelines could easily lead to uncertainties and arbitrary decisions for preparation and application of specific rehabilitation plan. Therefore, direct observation of the Jashar Pasha Mosque structure was an essential phase of the study in order to provide initial understanding of the structure as well as give the appropriate direction to the following examination. The analysis of structural errors began by mapping visible damage, noticing different kinds of materials, the decay, any structural irregularities and damages, while paying particular attention to pattern cracks phenomena (Fig. 3). During the time, behavior of all examined deficiencies has been monitored (observational approach), resulting in data to be used as basis for further action. In addition, architectural documentation, structural studies (seismic study) as well as cracks monitoring (behavior) should be provided before any restoration work takes place.
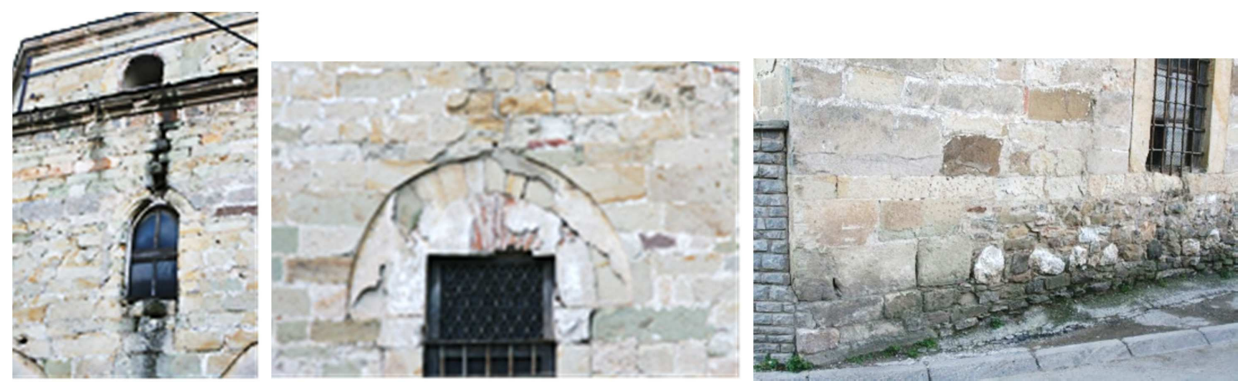

Fig. 3. On-site observation of cracks and decay/mold (Source: Violeta Nushi)

The report of structural integrity [9] in the case of Jashar Pasha Mosque, including the completion of diagnostic phase and safety evaluation, is presented through the diagram (Fig. 4) of modern structural analysis, based on a number of theories and mathematic diagnostics: theory of elasticity, theory of plasticity, ductility/to withstand the tensile stress, frame models, photogrammetry, laser-vibrometry, etc.)

In the event of any structural restoration decision, it should be kept in mind that the aim of the restoration is to preserve and reveal the aesthetic and historical value of the monument, respecting original materials [10].

Nevertheless, all aspects related to the obtained information, knowledge of what has occurred in the past, qualitative analysis - inductive procedure and analytic approach deductive procedure of the diagnosis, including the safety evaluation, and the decision to intervene, should be defined in the explanatory report in order to determine recommended corrective actions, for example, to fully understand the complexity of structural behavior of the building, particularly domed area, in order to apply 
appropriate repair techniques for the portico's enclosure (instead of partial and preventive intervention done in year 1990) (Fig. 2c).

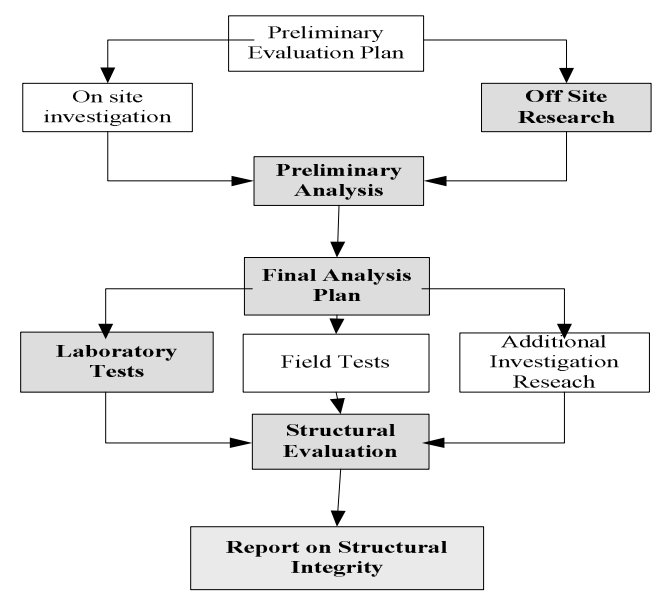

Fig. 4. The diagram of evaluation process used in Jashar Pasha Mosque case, based on the reference [8] (Source: Authors plot)

In addition, the structural damage and seismic vulnerability is attributed to the effect of cumulative damages resulting from past earthquakes, the aging process and adverse environmental conditions that progressively reduced the strength of the construction materials, possible faults of past repairs and interventions, possible soil changes causing damage to the building foundation, possible weakness inherited by the original structural materials and system to resist earthquake loads [11]. Therefore, main concepts of the International COuncil on MOnuments and Sites (ICOMOS) guidelines should be accepted by the accreditation bodies when applied the remedial measures, including: minimum intervention, conserving as found, honest repairs, sympathetic repairs and reversible alterations [12].

For the fact that every building has its different set of structural, economic and social constraints, it is occasionally possible to apply all of the above concepts, whilst recognizing that a low score does not necessarily represent the bad conservation or restoration [13]. Therefore, as per preliminary evaluation of conservation plan for the Jashar Pasha Masque, its structural restoration and seismic strengthening should consider the following main requirements:

a) the important role to be given to preservation of the aesthetic, architectonic and historical value as well as keeping the building operational;

b) enhance the outdoor and indoor strength, firmness of the walls;

c) any free standing element to be strengthened (minaret, portico) in order to withstand applied forces;

d) all walls to be efficiently tied together to form a box system, avoiding the separation of joints during earthquakes; 
e) on the floor and roof levels, rigid lateral loads system which transmits the inertia forces to the walls, should be created;

f) capacity of the foundation system should be enhanced to be able to stand excessive forces due to the earthquakes.

\section{Decisions, measures taken and materials used during the last intervention}

Due to the lack of application of professional standards for conservation/restorations during pervious restoration, a number of debates took place, especially in the case of Jashar Pasha Mosque. Therefore, political consensus between users, donors and cultural heritage authorities was one of the key issues to success. The key of successful restoration was the choice of materials and techniques used, as well. Techniques are classified into two categories: reversible and irreversible. Materials used in reversible intervention improved very few restrictions; hence the materials used in irreversible interventions impose the following two additional restrictions: compatibility of the new materials with the original restrictions and very long-term durability of the new materials [14]. The analysis or summary to follow, contains some of main restoration decisions for problems already identified, which were implemented during the most recent restoration and intervention performed in 2016 by Turkish International Cooperation and Coordination Agency (TIKA) under the supervision of the Kosovo Institute for Protection of Monuments, Ministry of Culture, Youth and Sport in Kosovo [3].

Main problems identified could be summarized as follows: problems in the structure, around the mosque, in the exterior on the façades, on the top cover of the mosque, on the Minaret, in the interior of the mosque.

In more specifics this could be elaborated with the summary of the following intervention decisions and completions (Fig. 5):

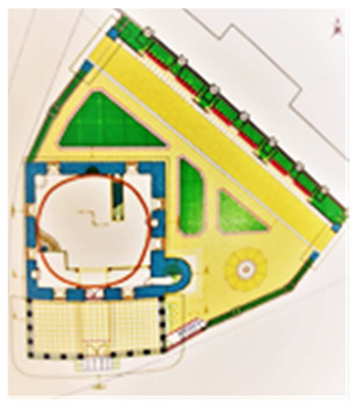

a)

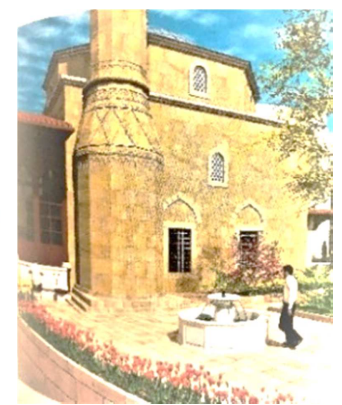

b)

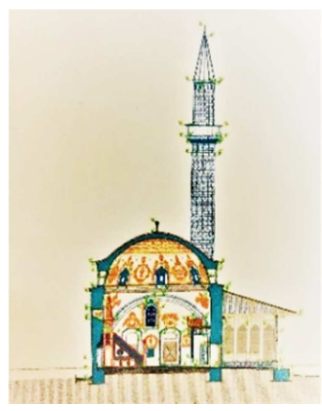

c)

Fig. 5. Few most recent restoration details, after 2016: a) the site layout and the communication paths; b) the façade, minaret and windows; c) intersection with interior details (Source: KIPM/TIKA project, reference [3], provided by the Ministry of Culture, Youth and Sports/MCYS) 
- Moving the vehicle road away from the mosque by narrowing it and expanding the pedestrian path. This road is currently used for parking, only;

- The courtyard wall and flooring are constructed and made around the structure, using the source of specific country building materials;

- 'tree type' plants are not used in the green areas around the building, as their roots might damage the structure, instead lower type plants including grass-, and various flowers are planned;

- storm water drainage has been created for the removal of rain, snow and surrounding waters, avoiding the perimeter of the structure;

- Masonry stone repairs on the façade have been performed using andesite type of rocks that show textural and formational compliance with original material (the same has been obtained from local sources around the village of Samadrezha near Vushtri, $15 \mathrm{~km}$ from Prishtina);

- Lower windows of the prayer hall have been reconstructed according to the traces of the structure. The bending occurring in the iron railings has been corrected and painted with protective paint;

- Ignimbrite or travertine type of rocks showing the textural and formation compliance with the original material, are used on the walls where needed (obtained from the local sources);

- The source of water (known as shadirvan) in the mosque courtyard has been reconstructed;

- Certain fissures and cracks recommended by civil engineers, will stop the opening of the frame of the dome, while the tensioning operation is made in the frame of the dome using steel metal strips, cables and Fiber Reinforced Plastic (FRP) [15];

- Windows inside the mosque are constructed in accordance with renovation project, as well as renewed losses in the skylights;

- Painting details during the last intervention have been removed by experts revealing original decorations. The varnished parts were completed with the same material and painting techniques, again by expert teams;

- the ventilation holes and ducts were re-opened and existing wooden floor was renewed following the renovation project recommendations and standards;

- Having in mind that the organic filling found in the original plaster has difficulties in terms of material supply and application, fiber or equivalent material was used in the repair process. Aggregates consisting of the fine sand carbonate (with size of 250-1000 nm), limestone powder, volcanic rock powder, lime plaster consisting of small grained bricks fractures, are used in the repair of original plaster applications of the stone and brick masonry surfaces (window arches, brick pillars bearing the prayer hall of the mosque, brick dome masonry, dome frame) [16], all in accordance with the original structure;

- The majority of the rubble masonries remained original. These parts have been protected using the brick fracture contribution, recommended both for compatibility with original materials and for the reduction of intense salinity impact carried with humidity in those parts [15];

- Reinforcement of cracks and fissures has been filled using a plaster consisting of ethyl silicate, stone or marble powder (with a practice size of 125-250 nm) 
and hydraulic lime. The appropriate color pigment was added to the surfaces, where needed;

- Plastic additions are made to the partial losses within architectural elements in the structure, as cornices, doors and window frames, as well as marble pool, by using hydraulic lime-based plaster compatible with the original content, color and texture;

- Bounding of fractured parts: Stainless steel reinforcement was required in specific points during the bonding of the fractures with high weight and stress, in terms of durability of the process. (Fig. 6).

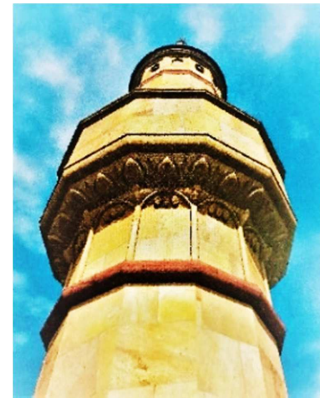

a)

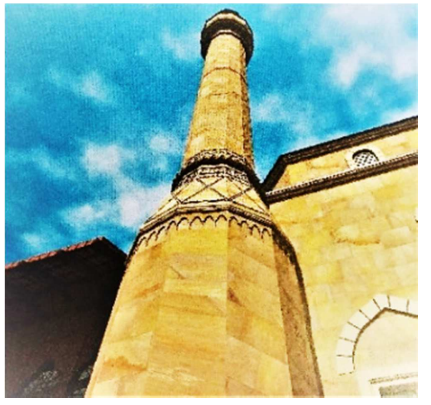

b)

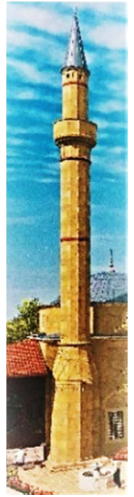

c)

Fig. 6. Details of Minaret after the restoration as per the project in 2016 (Source: KIPM/TIKA project, reference [3], provided by the Ministry of Culture, Youth and Sports/MCYS

The result of the most recent restoration summarized above [3], managed to extend the lifespan of the building with valuable architectural heritage components, trying to preserve the same and allow proper maintenance in the future, as well.

\section{Conclusion}

The process of restoration of Jashar Pasha Mosque should be considered an example to be followed and further improved, leading towards a better preservation of aesthetic and historical values of the cultural heritage buildings in Kosovo, in general. While respecting original materials, structural behavior and the use of modern materials and techniques, the results already achieved in the specific case, with the intention to be attained in other examples, will best serve the main principles of conservation.

Restoration of a monument is a complex process which demands cooperation and multidisciplinary field operations, including: restoration-conservation architect, structural engineer, chemical engineer, archeologist, as well compatible methods and well-equipped laboratories. The key of successful restoration is the appropriate choice of materials and techniques classified in two categories: reversible and irreversible. 
The reversible restoration techniques permit easy corrective action at a later stage if necessary and impose very few restrictions on the structure. Their advantages are in the cases of proven inefficiency or low durability, with possibility to be withdrawn without damage to the original fabric (if better techniques or materials are developed, the same can be replaced easily). Hereafter, the irreversible restoration techniques could be considered as permanent and cannot be undone without damage to the original fabric. Their advantage is in cases when it is necessary to re-establish the structural integrity of the building.

In the case of this study and analysis, the use of reversible restoration techniques as: strengthening the arches and dome by ties or using fiber reinforced plastic components, respecting the behavior of original structural system of the building, as well as irreversible techniques, as: deep rejoining, rebuilding parts of the facade walls (if parts have collapsed), adjoining new stones across the cracks, stitching of new bars on the walls, reinforcement of masonry walls by incorporating steel bars of pre-stressed tendons or 'smart materials', strengthening the foundation/underpinning, etc.

This study and analysis opens up paths for future examination of principles, methods and materials, aiming to better serve the entire process of restoration and conservation in the cases of historical architectural heritage.

\section{Acknowledgement}

The information about the intervention project in 2016 was provided by the Ministry of Culture, Youth and Sports of Kosovo (MYCS), Kosovo Institute for Protection of Monuments (KIPM).

\section{References}

[1] Feilden B. M. Conservation of historic buildings, Elsevier, Oxford, 2003.

[2] Sylejmani M., Medvegy G., Beqiri L. Spatial layout of the functions in Kulla, Pollack Periodica, Vol. 12, No. 1, 2017, pp. 159-170.

[3] Architectural documentation of Jashar Pasha Mosque, Turkish International Cooperation and Coordination Agency (TIKA), Kosovo Institute for Protection of Monuments (KIPM), Ministry of Culture, Youth and Sports (MYCS), Prishtinë, 2016.

[4] Cultural heritage without borders - Albania, http://chwb.org/albania/wp-content/ uploads/sites/ 4/2015/03/CHwB_Portfolio_2015_eng_low.pdf (last visited 26 February 2018).

[5] Cultural heritage without borders - Kosovo, http://chwb.org/kosovo/activities/preservationprizren-fortress/ (last visited 26 February 2018).

[6] Database of Cultural Heritage of Kosovo, The mosque of Jashar Pasha (Photo), https://dtk.rks-gov.net/tkk_objekti_en.aspx?id=8633 (last visited 4 February 2018).

[7] Kosovo local guide, http://kosovolocalguide.com/one-day-tours/prishtina-tour.html, (last visited 4 February 2018).

[8] IRPP/SAAH Integrated rehabilitation project plan/Survey of the architectural and archaeological heritage, Council of Europe, Strasburg, 2004/2007, adapted by the Ministry of Culture, Youth and Sports (MCYS), Kosovo/UNMIK, Prishtina, 2007. 
[9] Fitzsimons N., Colville J. Diagnosis and prognosis of structural integrity, Conservation of Historic Stone Building and Monuments, National Academy Press, Washington DC, 1982.

[10] ICOMOS Charter, International Charter for the Conservation and Restoration of Monuments and Sites (the Venice Charter 1964), Venice, 1964.

[11] Penelis G. Structural preservation of historical buildings in seismic area, Progress in Structural Engineering and Materials, Vol. 4, No. 1, 2002, pp. 64-73.

[12] ICOMOS Charter, Principles for the Analyzes, Conservation and Structural Restoration of Architectural Heritage, Zimbabwe, 2003.

[13] Richardson C. Conservation of Structures, Cambridge, 2003.

[14] National Information Centre of Earthquake Engineering, https://www.nicee.org/iaee/E Chapter9. pdf (last visited 26 February 2018).

[15] Orban Z. Temporary strengthening of steel bridge element with FRP sheet, Pollack Periodica, Vol. 9, No. 2, 2014, pp. 35-44.

[16] Török B., Len A., Orbán Z. Salt content analysis of historic masonries with SEM, Pollack Periodica, Vol. 12, No. 3, 2017, pp. 99-108. 